\title{
Homesickness Experience, Distress and Sleep Quality of First-Year University Students Dealing with Academic Environment
}

\author{
Valeria Biasi ${ }^{1^{*}}$ \\ Luca Mallia ${ }^{1,2}$ \\ Paolo Russo ${ }^{3}$ \\ Francesca Menozzi ${ }^{1}$ \\ Rita Cerutti ${ }^{4}$ \\ Cristiano Violani ${ }^{5}$ \\ 1 "Roma Tre" University \\ ${ }^{2}$ Department of Movement, Human and Health Sciences, \\ University of Rome "Foro Italico" \\ ${ }^{3}$ Department of Experimental, Diagnostic and Specialty Medicine - DIMES, \\ University of Bologna, Bologna, Italy \\ ${ }^{4}$ Department of Dynamic and Clinical Psychology, \\ Sapienza, University of Rome \\ ${ }^{5}$ Department of Psychology, Sapienza, University of Rome
}

${ }^{*}$ Corresponding Authors

Doi: 10.2478/jesr-2018-0001

\section{Abstract}

The literature shows that homesickness can have a negative impact on different areas of psychological functioning such as cognitive, emotional, behavioral, physical and social ones. The study, conducted on a sample of first-year university students, aimed to test a model hypothesizing that two distinct dimensions of homesickness, attachment to home and disliking university, could have both direct and indirect effects on their psychological distress and sleep difficulties. Two hundred and seventy-seven first-year students (70.4\% Female) living away from home (mean age= 21.3, $S D=2.7$ ) were included in the study and filled out questionnaires assessing homesickness, psychological distress and sleep difficulties. Structural Equation Model (SEM) analysis confirmed that the two homesickness dimensions worked differently since only the one relating to new place adjustment difficulties (i.e. disliking the university) resulted having both direct and indirect effects on students' sleep difficulties. Although female students reported higher levels of psychological distress compared to males, the multi-group SEM analysis showed that the pattern of multivariate relationships linking the two dimensions of homesickness, psychological distress and sleep difficulties, was invariant across gender. The results of the present study suggest that university counselling and guidance services should quickly screen students experiencing homesickness and offer effective counselling programs focusing on enhancing their capacities to deal with the new academic environment.

Keywords: Homesickness; First-year Students; Psychological distress; Sleep Difficulties; Structural Equation Model (SEM) 


\section{Introduction}

Homesickness is a complex phenomenon that has received some attention in the scientific literature over the last two decades for its possible impact on emotional, cognitive, social and somatic individual functioning (Stroebe et al. 2015). Fisher (1989) systematically analyzed homesickness in populations of non-resident students, highlighting the two key elements of the phenomenon. Firstly, preoccupation with family, friends, home and routines; and, secondly, the attitude towards the new environment. In a review, Van Tilburg and colleagues (Van Tilburg et al. 1996) suggested that, as well as phenomena such as nostalgia, grief or separation anxiety, feelings of sadness, ruminative and obsessive thoughts about home, and the desire to return home are peculiar features of homesickness. The separation from home itself does not necessarily have a negative impact, but could be a risk factor for vulnerable people, who may experience an increase in depressive or anxiety symptoms and a negative effect on their health (Thurber and Walton, 2012). In a clinical perspective, homesickness can be conceived as related to Adjustment Disorder of the DSM-IV, since it can be considered a maladaptive response to an identifiable psychosocial stressor. However, if homesickness is not severe enough to impair daily activity, it should be considered as a normal reaction to being away from home (Van Tilburg et al. 1996). Recently, Stroebe and colleagues (2016) proposed a Dual Process Model of Homesickness (DPM-HS) by independently treating the two elements of separation from home and relocation, since they involve dual regulatory processes that may co-occur and interfere with one another. The authors likened homesickness to a "minigrief" and defined it as "a negative emotional state primarily due to separation from home and attachment persons, characterized by longing for and preoccupation with home, and often with difficulties adjusting to the new place." (Stroebe et al. 2016, p.7).

Homesickness has been investigated under various conditions in which there is a move away from home either for a long period or permanently, such as with migrants, or for a short term, as in the case of military personnel, foreign employees, hospitalized children or non-resident university students (e.g. Stroebe et al. 2015). The transition to university, for example, is a life-event that could have negative effects on psychological functioning (e.g., Hamaideh 2011; Pellicer et al. 2002), and the move away from the family could be an additional stress factor for non-residential students, who may perceive their entrance to university as stimulating, but also stressful (Fisher and Hood 1987). Additional elements that can increase the loneliness of non-residential students include the discrimination perceived by foreign students and their difficulty to integrate in the academic context (Poyrazli and Lopez 2007).

Homesickness is a cross-cultural phenomenon and it may occur at any age and in a variety of situations. For these reasons, it is difficult to estimate its prevalence (Stroebe et al. 2015). Fisher (1989) highlighted that the prevalence in the general population of individuals is between 50 and $75 \%$, while the prevalence of the worst cases is estimated at between 10 and $15 \%$. Some studies on homesickness in student populations have pointed to a cultural variability. For example, there is a higher prevalence of homesick students in Turkey $(77 \%)$ than in the United States $(19 \%)$ (Carden and Feicht 1991), or a higher prevalence in the United Kingdom (80\%) than in the Netherlands $(50 \%)$ (Stroebe et al. 2002). In a study on Italian university students, Scopelliti and Tiberio (2010) found a difference in feelings of homesickness between resident and non-resident students, with $74 \%$ of non-resident students reporting feeling homesick in the last 4 weeks.

\subsection{Impact of homesickness on psychological well-being}

The literature shows that homesickness can have a negative impact on different areas of psychological functioning such as cognitive, emotional, behavioral, physical and social ones. In particular, homesickness can be characterized by negative thoughts about the new environment, by obsessive thoughts of one's original environment, which is often idealized, and by rumination. The symptomatology mainly includes depression and anxiety, and may come about with a state of apathy, withdrawal and lack of interest; loneliness, nervousness, insecurity and loss of control may also appear, as well as psychosomatic disorders (Archer et al. 1998; Stroebe et al. 2015; Van Tilburg et al. 1996). Among students, homesickness can reduce their ability to concentrate, cause 
lack of memory and induce social isolation and difficulties in adapting to university life; it has been shown that high levels of homesickness can trigger dropout (Fisher and Hood 1987; Thurber and Walton 2012). In a study with non-resident first-year university students, Urani and colleagues (Urani et al. 2003) showed a correlation between social anxiety and homesickness at the beginning of the academic semester: however, these feelings decrease over time. Moreover, students who have a higher level of social anxiety have more difficulty in developing social relationships, thus being more vulnerable to homesickness (Urani et al. 2003). Analyzing a sample of first-year college students, Seligman and Wuyek (2007) showed that $21 \%$ of students have symptoms of Separation Anxiety Disorder, which may affect their academic careers. Given the scale of the phenomenon, homesickness - which in itself is a normal feeling - can be considered problematic in situations where it causes significant distress, when it negatively affects daily routine or when it becomes chronic (Thurber and Walton 2012; Van Tilburg et al. 1996).

\subsection{The present study}

The past literature has clearly shown the negative impact that homesickness can have on the wellbeing of many university students. More recently, Stroebe and colleagues (2016) called for a deeper understanding of the different impact that the two aspects of homesickness (i.e. homerelated loss and adjustment to the new place) could have when they are considered separately. Accordingly, in the present study we evaluated the different impact of these two dimensions of homesickness on the onset and maintenance of sleep problems. Several studies have pointed out that a significant number of university students report poor sleep quality and quantity after enrollment, and generally have difficulties in falling asleep and in maintaining sleep (e.g., Lund et al. 2010; McKnight-Eily et al. 2011). However, to the best of our knowledge, no study has yet systematically investigated the influence of homesickness factors on sleep-related problems experienced by university students.

The present study aimed to assess the relations between homesickness, psychological distress (i.e. depression, anxiety and somatic problems) and sleep difficulties in a sample of firstyear university students. More specifically, with reference to the DPM-HS of Stroebe and colleagues (2015), the study tested a model hypothesizing that the two distinct dimensions of homesickness - namely, attachment to home and disliking the university - would have a distinct impact on both psychological distress and sleep difficulties (see Figure 1). We hypothesized that attachment to home would have only an indirect impact on sleep difficulties, through its direct impact on students' psychological distress. Conversely, disliking the university would have both a direct and indirect effect on students' sleep difficulties. In fact, it is plausible that the adjustment difficulties relating to the new environment might not only affect students' distress, but also change their life style and habits, directly contributing to their sleep difficulties. Furthermore, the study aimed to test whether these hypothesized effects were invariant across male and female first-year students.

\section{Methods}

\subsection{Sample and Procedure}

The present study is part of a broader online survey promoted by the Psychological Counselling and Guidance Service of "Roma Tre" University. This survey aimed to analyze the academic experience and psychological distress of first-year university students. Specifically, all the first-year university students taking part in this online survey who reported living in Rome for at least one month and away from home responded to specific questionnaires about homesickness and were included in the present study. Overall, 277 students $(70.4 \%$ females) aged $18-30$ years (mean age= $21.30, S D=2.73$ ) resulted eligible for the present study and were included in the analysis. 


\subsection{Measures}

The students were invited by email to fill in an anonymous online questionnaire in February-March 2015. The students were asked for information on their sociodemographic characteristics and their academic experience

The intensity of homesickness was measured by means of the Homesickness Questionnaire (HQ-Archer et al., 1998) - a 33-item questionnaire measuring two main factors: (1) dislike of the university (e.g., "I hate this place") and (2) attachment to home (e.g., "I can't help thinking about my home"). Past research (i.e. Archer et al. 1998) empirically attested good reliability for both scales $(\alpha=.85$ and .83 , respectively). The two scales also showed good reliability for the current sample $(\alpha=.85$ and .83 , respectively). Each item was scored on a 5-point Likert scale ranging from 1 (Completely disagree) to 5 (Completely agree), with higher scores indicating more symptoms of homesickness.

Anxiety, Depression and Somatic problems were assessed by means of the DSM-oriented scales of the Adult Self Report (ASR), a questionnaire developed by Achenbach and Rescorla (2003) for people aged 18-59 years. The DSM-oriented scales consisted of ASR items identified as being very consistent with the DSM-IV categories (Achenbach and Rescorla 2003; Achenbach et al. 2005) and previously used in the Italian context (e.g., Lombardo et al. 2013). The Italian translation of the ASR was used (Ivanova et al. 2014). The three DSM-oriented scales showed a good internal consistency in the present sample $(\alpha=.85, .73, .82$ for the Depression, Anxiety and Somatic problems scales, respectively). For each item of the three scales, the students were asked to respond on a three-point scale ranging from 0 (Not true) to 2 (Very true or often true), with higher scores indicating greater psychological distress.

Sleep difficulties were evaluated by using the three items of the Symptoms Check List-90 (SCL-90, Derogatis 1983), assessing the difficulty in falling asleep at night, awakening too early in the morning, and having disturbed and bad sleep, along with two items of the Pittsburg Sleep Quality Index (Buysse et al. 1988) evaluating awakening during the night and daytime sleepiness. Overall, the students were asked to respond to what extent in the last month they had experienced each specific sleep difficulty by using a 5-point scale ranging from 1 (Not at all) to 5 (Extremely). Because of the high consistency of the items $(\alpha=.79)$, the responses of each item were aggregated into a single score ("Sleep Difficulties"), for which higher values indicated greater experience of sleep difficulties in the last month.

\subsection{Data Analysis}

Firstly, differences in the key variables of the study, across gender, were evaluated by means of ANOVAs. Secondly, bivariate associations between all the key variables were performed. Thirdly, the hypothesized model was tested by using a Structural Equation Modelling (SEM) procedure. The model's parameters were estimated by means of the Maximum Likelihood (ML) estimation method with MPLUS-7 software (Muthen and Muthen 2012), and the quality of the model was examined through fit indices estimates of the TLI (Tucker Lewis Index), CFI (Comparative Fit Index), RMSEA (Root Mean Square Error of Approximation), and SRMR (Standardized Root Mean Square Residual) (Hu and Bentler 1999). The three DSM-oriented scales of ASR were used as indicators of the latent variable representing psychological distress. The three items of the SCL-90 and the two items of the PSQI were included in the model as indicators of the latent variable representing students' sleep difficulties. For the two latent variables relating to homesickness, an item-parceling procedure was used (Kim and Hagtevt 2003) in which the items of each subscale were randomly grouped and averaged, yielding three separate indicators for each latent dimension. In order to analyze the indirect effects hypothesized, a SEM with the bootstrap method (i.e. 1000 bootstrap resampling) was used to establish the $95 \%$ confidence intervals (Cls) for the indirect effects (Preacher and Hayes 2008). Finally, a multi-group SEM analysis evaluating the invariance of the model across gender was also conducted. In line with the literature (e.g., Byrne 2008), we assessed the configural equivalence of the model (i.e., the number of factors and their loading pattern are invariant across groups), its measurement equivalence (i.e., all the factor loadings for 
each latent variable are invariant across groups) as well as its structural equivalence (i.e., the variance, covariance and path linking the latent variables are invariant across groups) ${ }^{1}$.

\section{Results}

\subsection{Gender differences across the key variables of the study}

With respect to the ANOVA, a statistically significant effect of gender emerged for Depression $\left(F_{(1,275)}=5.77 ; p=.02\right)$, Anxiety $\left(F_{(1,275)}=20.56 ; p<.001\right)$ and Somatic Problems $\left(F_{(1,275)}=19.74\right.$; $p<.001)$, while no differences were found for the two dimensions relating to homesickness (Attachment to home, $\mathrm{F}_{(1,275)}=.02 ; p=.88$; and Dislike of the university, $\mathrm{F}_{(1,275)}=2.45 ; p=.12$ ) and sleep difficulties $\left(\mathrm{F}_{(1,275)}=3.67 ; p=.057\right)$. As shown in Table 1 , the female students reported higher levels of Depression, Anxiety and Somatic problems, namely reporting an overall higher level of psychological distress than the male students.

\subsection{Associations between students' homesickness, psychological distress and sleep difficulties}

The bivariate correlations reported in Table 2 show that all the key variables are significantly associated with one another. More specifically, both dimensions relating to Homesickness are significantly associated with the different aspects of psychological distress, such as Depression $(r=.29$ and $r=.59$, respectively), Anxiety ( $r=.36$ and $r=.42$, respectively) and Somatic Problems $(r=.35$ and $r=.43$, respectively). Furthermore, both Attachment to Home and Dislike for the University are significantly associated with sleep difficulties ( $r=.27$ and $r=.44$, respectively). Finally, all the indicators of psychological distress are associated with students' sleep difficulties.

\subsection{Effects of students' homesickness on psychological distress and sleep difficulties}

The SEM analysis showed that, on the whole, the model tested fitted the data well $\left(X^{2}{ }_{(71)}=221.089\right.$, $p<.001$; CFI=.92; RMSEA=.087; SRMR=.053). The measurement parameters of the model's latent constructs were statistically significant (all loadings > .50). As shown in Figure 1, only the homesickness dimension measuring Dislike for the university showed a positive and significant relationship with students' psychological distress $(\beta=.67 ; p<.001)$. In turn, psychological distress revealed a positive and significant effect of students' sleep difficulties $(\beta=.70 ; p<.001)$. Otherwise, results showed no direct effects of either dimension of homesickness on sleep difficulties. Finally, analysis of the indirect effects showed a significant indirect effect of Dislike for the university on sleep difficulties through psychological distress $(\beta=.47, \mathrm{p}<0.001 ; \mathrm{Cl}=.280$ to .661$)$, while the indirect effect for Attachment to home was not significant $(\beta=.023, p=.80 ; \mathrm{C} . \mathrm{I}$. $=-.155$ to .201$)$. Overall, the model explains about half of the variance of psychological distress $\left(R^{2}=.45\right)$ and of sleep difficulties $\left(R^{2}=.54\right)$.

\subsection{The invariance of the model across male and female students}

The multi-group SEM analysis supported the hypothesis of configural equivalence of the model across gender $\left(X_{(152)}^{2}=371.342, p<.001 ; C F I=.90 ; \quad R M S E A=.102 ;\right.$ SRMR=.072) as well as the hypothesis of measurement equivalence. In fact, when the model was revised to include the

\footnotetext{
${ }^{1}$ In testing invariance, each model including a specific constraint (e.g., equivalence of the factor loadings) is nested into a model without this constraint, and thus the two models can be compared by the chi-square difference test, using the difference in their chi ${ }^{2}$ values and in their degrees of freedom. If the chi-square difference value is statistically significant, it suggests that the constraint included does not hold (i.e., is not equivalent) across groups. Conversely, if the chi square difference value is statistically non-significant, this finding suggests that the specific equality constraint included is tenable across groups. In order to establish the significance of the chi-square difference test, we set the critical p-level to 0.05 .
} 
constraints of loading equality across gender, the model's fit indices did not worsen significantly $\left(X^{2}\right.$ diff(10) $\left.=10.46 ; p=.40\right)$. Finally, the structural equivalence of the model across gender was also fully supported since the model's fit did not worsen either when the constraints of variance/covariance equality across gender were included $\left(X^{2}\right.$ diff(5) $\left.=9.73 ; p=.083\right)$, or when path equality constraints were included $\left(X_{\text {diff(5) }}^{2}=3.15 ; p=.68\right)$. Thus, the results suggested that all the relations hypothesized in the model were substantially the same for males and females. In other words, the psychological processes outlined in the model characterized male and female students equally well.

\section{Discussion}

The present study was conducted on first-year university students and aimed to explore the multivariate relationship between their experience of homesickness and some factors that could negatively affect their academic career, such as psychological distress and sleep difficulties. In particular, our study tested a model which, according to the DPM-HS of Stroebe and colleagues (2016), analyzed the distinct impact that the two dimensions of Homesickness - namely, Attachment to home and Dislike for the university - would have directly and indirectly on students' sleep difficulties, by means of a multivariate analytical approach (i.e. Structural Equation Model analysis).

Considering the results of the traditional, univariate analytical approach (i.e. bivariate correlations), the two dimensions of homesickness seem to have an effect on students' psychological distress and sleep difficulties, mainly confirming the past literature that has treated these two dimensions as indistinct aspects of homesickness (Stroebe et al. 2016). However, adopting a multivariate analytical approach, the results of the SEM analysis clearly showed that the two dimensions of homesickness have a different and distinct impact on students' psychological distress and their sleep difficulties, thereby partly confirming our specific hypothesis. In particular, the homesickness dimension relating to adjustment difficulties (i.e. disliking the university) only had an indirect effect on students' sleep difficulties, through its effect on students' psychological distress. Conversely, this dimension seems to have no direct impact on students' sleep difficulties. Furthermore, the dimension relating to attachment to home had no effect on either students' psychological distress or sleep difficulties. Finally, although female students reported overall higher levels of psychological distress with respect to male students, the pattern of multivariate relations linking the two dimensions of homesickness, i.e. psychological distress and sleep difficulties, was invariant across gender.

On the whole, the results of our study confirm the validity of the Dual Process Model of Homesickness (Stroebe et al. 2015) differentiating the two dimensions of Homesickness, Attachment to home and Disliking the university. The first captures the negative emotions arising from the separation from relevant attachment figures (i.e. attachment to home); the second captures the difficulties in adapting to the new environment (dislike the university). The two dimensions had different consequences in our sample of first-year students and affected their wellbeing and sleep quality in different ways. In particular, even if the univariate analytical approach (bivariate correlations) showed that the two dimensions are related to both students' psychological distress and sleep difficulties, only the dimension relating to adjustment to the new environment has a significant impact on these outcomes when the multivariate relation between key variables was considered (i.e. SEM analysis). These results are totally in line with previous empirical findings concerning different patterns linking the two dimensions of homesickness with several correlates. While the home-related dimension seems to concern intrusions (Archer et al. 1998) and worries regarding home problems (Fisher et al. 1984), the factor concerning the new place (i.e. adjustment difficulties) seems to be strongly related to depression (Stroebe et al. 2002), lack of perceived control and state anxiety (Flett et al. 2009).

Furthermore, the comparison of the results of the univariate analysis and multivariate ones pointed out as several past research (see Stroebe et al. 2015) based on the first approach possible tended to consider Homesickness as an unique dimension since they had not the possibility to capture the multivariate effects on these two distinct dimensions. Finally, the null effects found may be related to the specific time in which the assessment was carried out, and namely about four 
months after the beginning of the first-year students' academic year. It may be that at that at that moment in time, considering a multivariate point of view, the only variable of importance for the students' psychological distress and, consequently, for their sleep difficulties, concerned the adjustment difficulties relating to the new university environment. Future studies are needed in order to explore the multivariate effects of these two dimensions on the students' first year.

Overall, the results of the present study have important implications for planning prevention and treatment programs with university students. Although Stroebe and colleagues (2016) suggested dedicating equal attention to both home-related and new-environment stressors, our results suggest focusing mainly on the latter. In particular, prevention and treatment programs should focus on both male and female students in order to deal with their negative experiences with their new environment, and to enhance their capacities to deal with a new and challenging social and academic environment. Furthermore, the results show that adjustment difficulties in first-year students are related to psychological distress and sleep difficulties, which, if not adequately managed, could negatively affect the students' academic performance and career. Hence, it is fundamental for the university counselling and guidance services to quickly screen those students having difficulties in adjusting to their new environment and to offer them effective counselling programs (e.g., Biasi and Bonaiuto 2012; Biasi et al. 2015).

The present study is not devoid of limitations, primarily with regard to the cross-sectional design of the study. Future longitudinal studies need to replicate the predictive value of our results, following the first-year students along their career and analyzing the role of the two dimensions of homesickness on their well-being over time. In fact, as mentioned above, the specific time of the assessment within the students' career (i.e. about four months after the beginning of the first year) may have affected the results of our study. It is plausible that the impact of the two dimensions of homesickness on students' well-being can change during the first year. Future studies need to address these differences by using different assessment waves across time (e.g. at the beginning of the first year, at the end of the first semester, and at the end of the first year).

\section{References}

Achenbach ,T.M., Bernstein, A., \& Dumenci, L. (2005). DSM-oriented scales and statistically based syndromes for ages 18 to 59: linking taxonomic paradigms to facilitate multitaxonomic approaches. Journal of Personality Assessment, 84(1): 49-63.

Achenbach, T.M., \& Rescorla, L. A. (2003). Manual for the ASEBA adult forms \& profiles. Burlington, VT, USA: Research Center for Children, Youth, \& Families, University of Vermont.

Archer, J., Ireland, J., Amos, S.L., Broad, H., \& Currid, L. (1998). Derivation of a homesickness scale. British Journal of Psychology, 89(2), 205-221.

Beck, R., Taylor, C., \& Robbins, M. (2003). Missing home: Sociotropy and autonomy and their relationship to psychological distress and homesickness in college freshmen. Anxiety, stress, and coping, 16(2), 155166.

Biasi, V. and Bonaiuto, P. (2012). The Scientific Contribution of the Clinical Method in Educational Research. Journal of Educational, Cultural and Psychological Studies, 6, 107-127. http://dx.doi.org/10.7358/ecps2012-006-bias

Biasi, V., Bonaiuto, P., Patrizi, N. and Levin, J.M. (2015). The Effectiveness of Clinical Colloquium Established by the "Drawing Recall" Technique in University Counselling Services for Student Mental Health. Health, 7, 521- 532.

Buysse, D.J., Reynolds, C.F., Monk, T.H., \& Berman , S.R.(1989). The Pittsburgh Sleep Quality Index: a new instrument for psychiatric practice and research. Psychiatry Research, 28, 193-213.

Byrne, B.M. (2008). Testing for multigroup equivalence of a measuring instrument: a walk through the process. Psicothema, 20(4), 872e882.

Carden, A.I., \& Feicht, R. (1991). Homesickness among American and Turkish college students. Journal of Cross-Cultural Psychology, 22(3), 418-428.

Derogatis, L.R. (1983). SCL-90-R Administration, Scoring \& Procedures Manual-II. Towson, MD: Clinical Psychometric Research.

Fisher, S. (1989). Homesickness, cognition and health. Psychology Press.

Fisher, S., Frazer, N., \& Murray, K. (1984). The transition from home to boarding school: A diary-style analysis of the problems and worries of boarding school pupils. Journal of Environmental Psychology, 4, 211-221.

Fisher, S., \& Hood, B. (1987). The stress of the transition to university: a longitudinal study of psychological 
disturbance, absent mindedness and vulnerability to homesickness. British Journal of Psychology, 78(4), 425-441.

Flett, G.L., Endler, N.S., \& Besser, A. (2009). Separation Anxiety, Perceived Controllability, and Homesickness. Journal of Applied Social Psychology, 39(2), 265-282.

Kim, S., Hagtevt, K.A. (2003). The impact of misspecified item parcelling on representing latent variables in covariance structure modelling: a simulation study. Structural Equation Modelling, 10, 101-27.

Hamaideh, S.H. (2011). Stressors and reactions to stressors among university students. International Journal of Social Psychiatry, 57 (1), 69-80.

Hu, L.T., Bentler, P.M. (1999). Cut-off criteria for fit indexes in covariance structure analysis: conventional criteria versus new alternatives. Structural Equation Modelling, 6, 1-55.

Ivanova, M.Y., Achenbach, T.M., Rescorla, L.A., Turner, L.V., Ahmeti-Pronaj, A., Au, A., ... Zasepa, E. (in press). Syndromes of Self-Reported Psychopathology for Ages 18-59 in 29 Societies. Journal of Psychopathological Behavior Assessment.

Lombardo, C., Mallia, L., Battagliese, G., Grano, C., \& Violani, C. (2013). Perfectionism mediates the relationship between insomnia and depressive symptoms. Sleep and Biological Rhythms, 11 (2), 90-98.

Lund, H.G., Reider, B.D., Whiting, A.B., Prichard, J.R. (2010). Sleep patterns and predictors of disturbed sleep in a large population of college students. Journal of Adolescent Health, 46(2),124-132.

McKnight-Eily, L.R., Eaton, D.K., Lowry, R., Croft, J.B., Presley-Cantrell, L., Perry, G.S. (2011). Relationships between hours of sleep and health-risk behaviors in US adolescent students. Preventive Medicine, 53(45), 271-273.

Muthen, L.K., \& Muthen, B.O. (2012). Mplus User's guide (7th ed.). Los Angeles, CA: Muthen \& Muthen.

Pellicer, O., Salvador, A., \& Benet, I.A. (2002). Effects of an academic stressor on the psychological and immune response in the young males. Psicothema, 14 (2), 317-322.

Poyrazli, S., \& Lopez, M.D.(2007). An exploratory study of perceived discrimination and homesickness: A comparison of international students and American students. The Journal of Psychology, 141(3), 263-280.

Preacher, K.J., \& Hayes, A.F. (2008). Asymptotic and resampling strategies for assessing and comparing indirect effects in multiple mediator models. Behavior Research Methods, 40(3), 879-891.

Scopelliti, M., \& Tiberio, L. (2010). Homesickness in university students: the role of multiple place attachment. Environment and behavior, 42(3), 335-350.

Seligman, L.D., \& Wuyek, L.A. (2007). Correlates of separation anxiety symptoms among first-semester college students: An exploratory study. The Journal of psychology, 141(2), 135-145.

Stroebe, M., Schut, H., Nauta, M.H. (2016). Is homesickness a mini-grief? Development of a dual process model. Clinical Psychological Science, 4 (2), 344-358.

Stroebe, M., Schut, H., \& Nauta, M. (2015). Homesickness: A Systematic Review of the Scientific Literature. Review of General Psychology, 19 (2), 157-171

Stroebe, M., van Vliet, T., Hewstone, M., \& Willis, H. (2002). Homesickness among students in two cultures: Antecedents and consequences. British Journal of Psychology, 93(2), 147-168.

Thurber, C. A., \& Walton, E. A. (2012). Homesickness and adjustment in university students. Journal of American college health, 60(5), 415-419.

Urani, M.A., Miller, S.A., Johnson, J.E., \& Petzel, T.P. (2003). Homesickness in Socially Anxious First Year College Students. College Student Journal, 37(3), 392.

Van Tilburg, M.A., Vingerhoets, A.J., \& Van Heck, G.L. (1996). Homesickness: A review of the literature. Psychological medicine, 26(05), 899-912.

Van Tilburg, M., Vingerhoets, A.J., \& Van Heck, G.L. (1999). Determinants of homesickness chronicity: Coping and personality. Personality and Individual Differences, 27(3), 531-539. 


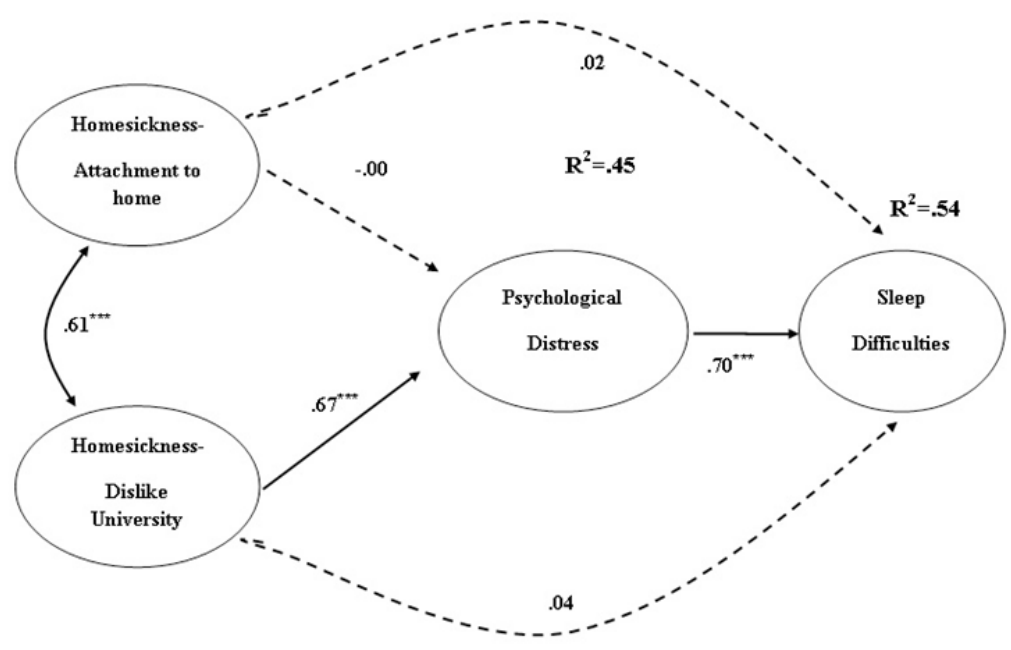

Figure 1. Graphic representation of the multivariate relations (by SEM analysis) between the variables considered: the two distinct dimensions of homesickness, i.e. attachment to home and disliking the university, have distinct impacts on both psychological distress and sleep difficulties.

Table 1. Means (SD) of the key variables across gender.

\begin{tabular}{|c|c|c|c|c|c|}
\hline & $\begin{array}{c}\text { Male } \\
\text { Mean (SD) }\end{array}$ & $\begin{array}{c}\text { Female } \\
\text { Mean (SD) }\end{array}$ & $\begin{array}{c}\text { Total } \\
\text { Mean (SD) }\end{array}$ & $\mathrm{F}$ & $p$ - level \\
\hline 1. Attachment to Home & $2.43(.59)$ & $2.55(.53)$ & $2.51(.55)$ & 2.45 & $p=.12$ \\
\hline 2. Dislike the University & $1.88(.67)$ & $1.90(.62)$ & $1.90(.63)$ & .020 & $p=.88$ \\
\hline 3. Depression & $.38(.34)$ & $.50(.37)$ & $.46(.36)$ & 5.77 & $p=.02$ \\
\hline 4. Anxiety & $.91(.46)$ & $1.17(.42)$ & $1.09(.45)$ & 20.56 & $p<.001$ \\
\hline 5. Somatic Problems & $.22(.33)$ & $1.71(.77)$ & $.37(.36)$ & 19.74 & $p<.001$ \\
\hline 6. Sleep Difficulties & $.43(.35)$ & $1.90(.75)$ & $1.84(.76)$ & 3.67 & $p=.057$ \\
\hline
\end{tabular}

Table 2. Bivariate correlations among the key variables of the study

\begin{tabular}{|c|c|c|c|c|c|}
\hline & 1 & 2 & 3 & 4 & 5 \\
\hline 1. Attachment to Home & & & & & \\
\hline 2. Dislike the University & $.57^{* * *}$ & - & & & \\
\hline 3. Depression & $.29^{* * * x}$ & $.59^{* * * *}$ & - & & \\
\hline 4. Anxiety & $.36^{* * *}$ & $.42^{* * *}$ & $.62^{* * *}$ & - & \\
\hline 5. Somatic Problems & $.35^{* m *}$ & $.43^{\mathrm{nat*}}$ & $.67^{* * *+}$ & $.54^{* * * x}$ & - \\
\hline 6. Sleep Difficulties & $.27^{+* t+x}$ & $44^{* * * x}$ & $.58^{* * *}$ & $47^{+* * x}$ & $.52^{n+* x}$ \\
\hline
\end{tabular}

Note." p level <.001 